\title{
Uso da túnica vaginal canina conservada em glicerina a $98 \%$ como curativo biológico no tratamento de feridas cutâneas produzidas em ratos Wistar*
}

\section{Use of canine vaginal tunic preserved in $98 \%$ glycerin as biological curative in the treatment of skin produced in wound Wistar rats}

\author{
Jéssica Frayle Campos, ${ }^{* *}$ Giovana Carvalho Vieira, ${ }^{* * *}$ Juliana Evangelista Bezerril, ${ }^{* * *}$ Tais Harumi de Castro Sasahara, ${ }^{* \star * *}$ \\ Paola Castro Moraes, ${ }^{* * * * *}$ Leonardo Martins Leal ${ }^{* * * * * * *}$
}

\section{Resumo}

Na procura por material alternativo no tratamento de feridas cutâneas, buscou-se com este estudo avaliar o comportamento da túnica vaginal canina conservada em glicerina a 98\% como curativo biológico no tratamento de feridas cutâneas provocadas experimentalmente em ratos. Foram utilizados 16 ratos Wistar, nos quais foram induzidas experimentalmente duas lesões cutâneas na região dorsal, sendo uma cranial e a outra caudal. Uma ferida serviu de controle, a qual não recebeu tratamento, a outra recebeu a túnica vaginal recobrindo toda extensão da lesão. A seleção de qual das feridas, cranial ou caudal, iria receber a membrana foi feita de forma aleatória. Os animais foram distribuídos em quatro grupos de igual número para análises clínicas, macroscópicas e histológicas decorridos três, sete, 14 e 21 dias de pós-operatório. Na avaliação clínica e macroscópica pode-se observar que o processo de reparação teve evolução semelhante tanto no grupo controle quanto no grupo membrana. Na análise histopatológica foi constatada grande quantidade de infiltrado inflamatório nos períodos iniciais, no entanto, decorridos 21 dias, a epiderme já se encontrava reparada, e em todos os momentos foi observada maior presença de tecido conjuntivo no grupo membrana, sugerindo maior precocidade na cicatrização. Deste modo, concluiu-se que a túnica vaginal canina pode ser utilizada como nova alternativa no tratamento de feridas cutâneas.

Palavras chaves: biomaterial, cães, cicatrização, cirurgia, pele.

\begin{abstract}
In the search for alternative material in the treatment of cutaneous wounds, this study aimed to evaluate the behavior of canine vaginal tunic conserved in glycerin $98 \%$ as a biological dressing in the treatment of cutaneous wounds provoked experimentally in rats. Sixteen animals were used in which two cutaneous lesions were caused in the dorsal region, one cranial and the other caudal. One wound served as a control which did not receive treatment, the other received the vaginal tunic covering all extension of the lesion. The selection of which of the wounds, cranial or caudal, would receive the membrane was made at random. The animals were divided into four groups of equal numbers for clinical, macroscopic, and histological analyzes after three, seven, 14 and 21 postoperative days. In the clinical and macroscopic evaluation, it can be observed that the healing process had similar evolution in both the control group and the membrane group. In the histopathological analysis, a large amount of inflammatory infiltrate was observed in the initial periods; however, after 21 days the epidermis was already healed, and at all times a greater presence of connective tissue was observed in the membrane group, suggesting a greater precocity in healing. Thus, it was concluded that the canine vaginal tunic can be used as a new alternative in the treatment of cutaneous wounds.
\end{abstract}

Keywords: biomaterials, dog, healing, skin, surgery.

\footnotetext{
*Recebido em 20 de janeiro de 2021 e aceito em 14 de abril de 2021.

**Médica Veterinária Autônoma; Maringá; Paraná; Brasil.

***Graduanda de Medicina Veterinária da Faculdade de Ciências Agrárias e Veterinárias - FCAV - UNESP; Jaboticabal; SP; Brasil. Autor para correspondência: giovana.carvalho@unesp.br

****Professora Doutora Assistente III no Centro Universitário de Mineiros - UNIFIMES - Departamento de Veterinária; Mineiros; GO; Brasil.

*****Professora Doutora na Faculdade de Medicina Veterinária e Zootecnia - FMVZ - USP - Departamento de Cirurgia; São Paulo; SP; Brasil.

******Professora Doutora na Faculdade de Ciências Agrárias e Veterinárias - FCAV - UNESP - Departamento de Clínica e Cirurgia Veterinária; Jaboticabal; SP; Brasil.

*******Professor Doutor no Centro Universitário Ingá - Uningá - Departamento de Medicina Veterinária; Maringá; PR; Brasil.
} 


\section{Introdução}

Lesões de pele são muito frequentes na rotina clínico-cirúrgica, seja na medicina veterinária ou medicina humana (Scheffer et al., 2013; Amaral et al., 2016). Usualmente as feridas cutâneas traumáticas podem ser tratadas por primeira, segunda ou terceira intenção (Monteiro et al., 2007; Castro et al., 2009; Burgos et al., 2016), sendo que diversas modalidades de tratamento já foram propostas.

Quando tratadas por segunda intenção, busca-se o controle microbiano da ferida com o uso de antissépticos e antibióticos; no entanto, em alguns casos, essas substâncias tópicas podem prejudicar a cicatrização. Em contrapartida, soluções salinas isotônicas que também utilizadas, não causam danos à pele; todavia, não possuem propriedades bactericidas ou bacteriostáticas (Rahal et al., 2001). Com isso, novas alternativas vêm sendo estudadas para o tratamento das feridas, sendo que o uso de curativos biológicos com membranas de origem animal merece destaque (Silva et al., 2004; Busnardo et al., 2009; Leal et al., 2014).

Os biomateriais são implantes orgânicos, constituídos basicamente de colágeno, os quais aceleram a formação de tecido de granulação e epitelização; e ainda podem apresentar características antibacterianas e analgésicas (Falcão et al., 2002). Isso foi verificado no uso de membrana amniótica no reparo de feridas cutâneas em equinos (Oliveira \& Alvarenga, 1998). Ademais, foi avaliado ainda o uso da túnica vaginal bovina no reparo de hérnias umbilicais em ovelhas, o qual demonstrou ser um material biocompatível e adequado para este tipo de procedimento (Abass, 2008). Outros pesquisadores concluíram que a túnica vaginal canina autógena, a fresco, aplicada em ceratoplastia lamelar, mostrou-se eficaz na reparação corneana (Galera et al., 2000), bem como alternativa para reforço do diafragma pélvico e tratamento de hérnia perineal em cães (Faria et al., 2020).

Quanto ao armazenamento, no que se refere aos meios de conservação de túnicas espermáticas, estudo afirmou que a glicerina a 98\% preserva a arquitetura tecidual básica da membrana e as suas estruturas celulares (Oliveira et al., 2015) e também, permite com que as membranas acondicionadas atuem como arcabouço, orientando o crescimento tecidual no leito receptor (Raiser et al., 2001). Além disso, a solução de glicerina a $98 \%$ é um agente fixador e desidratante dotada de propriedades antissépticas com amplo espectro de ação, exceto sobre formas bacterianas esporuladas (Daleck et al., 1988)

Os ratos são utilizados há décadas em pesquisas médicas e veterinárias (Luciano \& Mello, 1988; Brun et al., 2002; Borsari et al., 2014). Tal espécie possui tamanho adequado, ampla distribuição geográfica, adaptação a ambientes variados, nutrição variada, entre outras características, que atendem as condições atribuídas à modelo experimental animal (Ferreira et al, 2005).

Deste modo, objetivou-se avaliar o uso da túnica vaginal canina conservada em solução de glicerina a 98\% como curativo biológico em ratos por meio de análises clínicas, macroscópicas e histológicas.

\section{Material e métodos}

As túnicas vaginais foram colhidas a partir de cães adultos jovens, entre 5 e $30 \mathrm{~kg}$, submetidos a procedimentos de orquiectomia no Hospital Veterinário da UNINGÁ. A coleta da túnica ocorreu por meio de uma abertura em direção ao eixo longitudinal dos testículos, seguida pela identificação e retirada da túnica vaginal com tesoura de Metzembaum (Figura 1). Em nosso estudo, as túnicas variaram, entre 5 e $20 \mathrm{~cm} 2$, diretamente proporcional ao porte do animal. As túnicas foram imediatamente lavadas com solução salina estéril e conservadas por imersão em solução de glicerina a $98 \%$ em recipientes previamente esterilizados. As membranas permaneceram submersas na solução preservadora por 30 dias, em temperatura ambiente, até o momento da sua utilização (Oliveira et al., 2015).

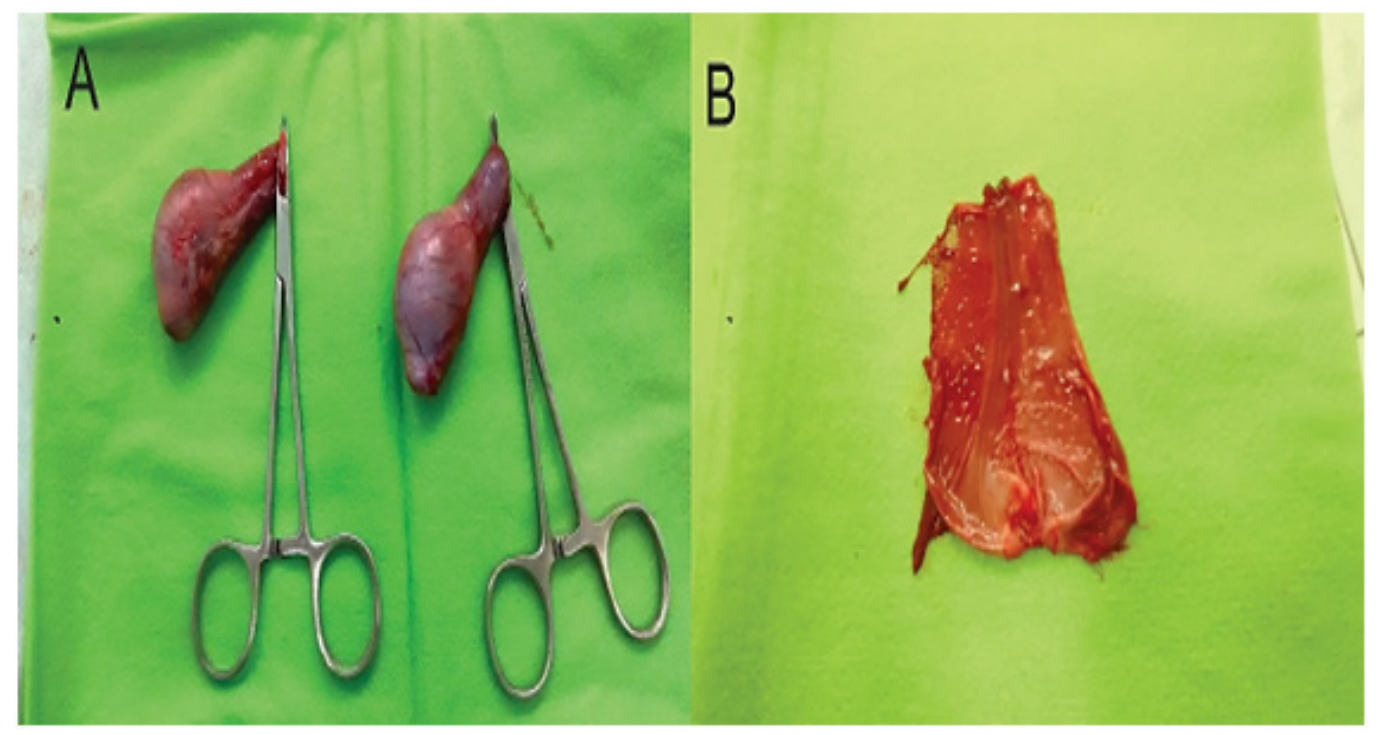

Figura 1: Imagens fotográficas de testículos de cães. Em A, nota-se o testículo recoberto pela túnica vaginal após orquiectomia. Em B, a túnica vaginal após ser dissecada. 
Foram utilizados 16 ratos Wistar, machos adultos, com peso entre 150 e 250 gramas, baseado na quantidade de animais utilizados em outros dois experimentos (Marques et al., 1996; Busnardo et al, 2009). Estes animais foram obtidos do Biotério da Universidade Estadual de Maringá, e acondicionados em gaiolas individuais, localizadas no Biotério do Centro Universitário Ingá, onde receberam ração e água à vontade. Neste ambiente, havia apenas os animais contidos no experimento, sendo que esses foram separados em quatro grupos $(n=4)$ de igual número para avaliações clínicas, macroscópicas e histológicas, decorridos três, sete, 14 e 21 dias de pós-operatório (G3, G7, G14 e G21, respectivamente).

Durante o período de quatro horas anterior ao procedimento, os animais foram submetidos a jejum alimentar e hídrico, e 30 minutos antes da intervenção cirúrgica foram administrados antibiótico enrofloxacina $(10,0 \mathrm{mg} / \mathrm{Kg})$, anti-inflamatório cetoprofeno $(3,0 \mathrm{mg} / \mathrm{Kg})$ e analgésico cloridrato de tramadol $(2,0 \mathrm{mg} / \mathrm{Kg}$ ) todos por via intramuscular (Busnardo et al, 2009). Conforme realizado Leal et al. (2014), os ratos foram submetidos à anestesia geral na dose de $50 \mathrm{mg} / \mathrm{Kg}$ de cetamina associada a $20 \mathrm{mg} / \mathrm{Kg}$ de xilazina administrados por via intramuscular. Com o animal devidamente anestesiado e após realização de tricotomia ampla da região dorsal, foram delimitadas duas feridas de $1,0 \times 1,0 \mathrm{~cm}$ na região dorsal, distantes uma da outra cerca de $1,0 \mathrm{~cm}$, sendo uma cranial (imediatamente caudal as escápulas) e a outra caudal (Figura 2). Tal espaçamento foi determinado, hipoderme até a superfície externa das fáscias musculares. A túnica vaginal foi removida do frasco 15 minutos antes de sua implantação, lavada abundantemente com solução salina estéril a $0,9 \%$ para remoção do excesso de conservante e depois permaneceu imersa na mesma solução por 10 minutos com o objetivo de hidratar a membrana (Oliveira \& Alvarenga, 1998).

No pós-operatório, não foram realizadas bandagens ou curativos nas feridas, uma vez que, buscou-se observar a evolução direta da cicatrização sem interferência da proteção propiciada pelo uso de bandagens. Desse modo, iniciou-se o período de análises clínicas dos grupos. Quanto a avaliação macroscópica das feridas, foram observados os seguintes aspectos: presença de conteúdo purulento, hiperemia, formação de tecido de granulação e crostas, bem como o aspecto das membranas, se estavam úmidas, transparentes, ressecadas e aderidas a ferida.

Decorrido os dias previstos para cada grupo (G3, G7, G14, G21), os animais foram submetidos à eutanásia mediante a administração de $100 \mathrm{mg} / \mathrm{Kg}$ de cetamina associada com $20 \mathrm{mg} / \mathrm{kg}$ de xilazina, por via intramuscular seguida injeção intracardíaca de cloreto de potássio $19 \%$ até o óbito do paciente (Leal et al., 2014).

Após a eutanásia foram removidos fragmentos de $1 \times 1 \mathrm{~cm}$ do local implante/tecido, observando se houve a formação de aderências ao subcutâneo e musculatura. Tais amostras teciduais foram acondicionadas em frascos universais com solução isotônica tamponada de formaldeído a 4\% para fixação. Após a fixação,

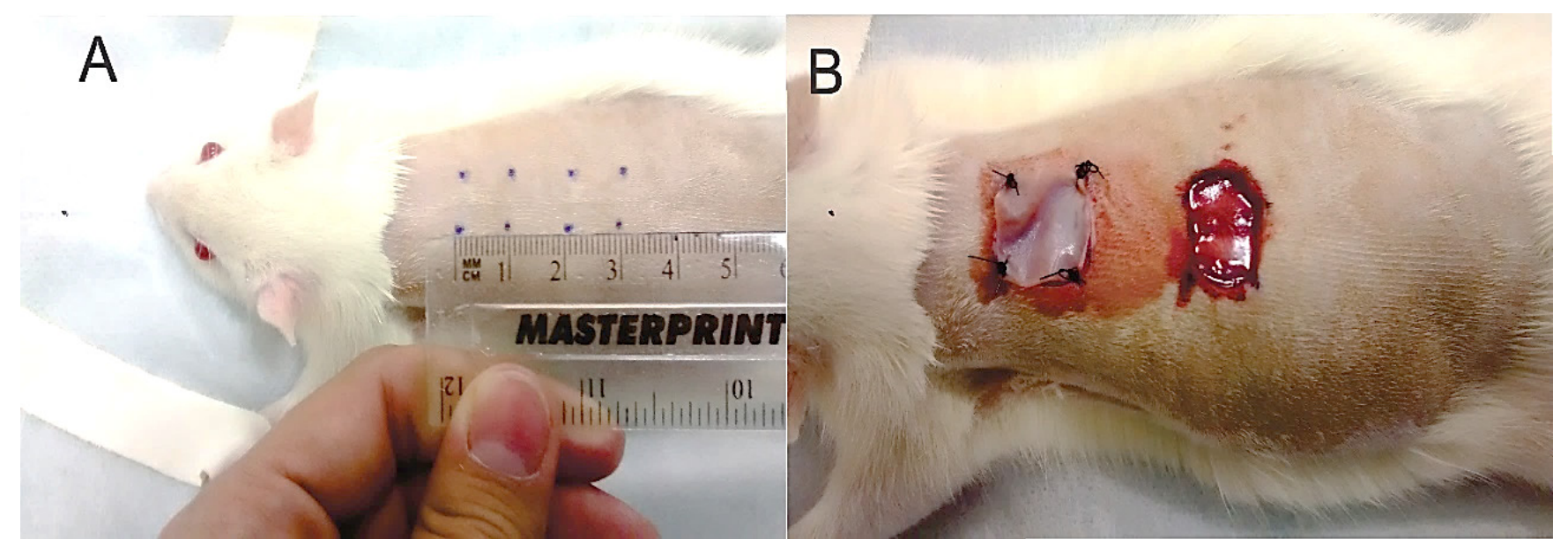

Figura 2: Imagens fotográficas transoperatórias de ratos Wistar. Em A, realização da marcação do tamanho da ferida, sendo 1,0 x 1,0cm. Em B, após ser realizado a ferida cutânea e fixado a túnica vaginal com um ponto simples separado em cada canto com fio nylon 4-0.

indiretamente, com base no tamanho dos animais, de modo que dificultasse 0 acesso às feridas pela boca e membros.

Uma ferida serviu de controle, a qual não recebeu tratamento, a outra recebeu a túnica vaginal (tratado) recobrindo toda extensão da lesão, sendo fixada com um ponto simples separado em cada canto com fio nylon 4-0 (Figura 2). A seleção de qual das feridas, cranial ou caudal, iria receber a membrana foi feita de forma aleatória, para que não houvesse influência da região anatômica. A pele das áreas demarcadas foi removida com uma profundidade que compreendesse a epiderme, derme, os tecidos foram embebidos em parafina e levados para um micrótomo automático onde foram seccionados em cortes de 5 micrômetros de espessura. Por fim, os fragmentos foram fixados em lâmina e submetidos às colorações por Hematoxilina e Eosina (HE) para análise histológica (Junqueira \& Carneiro, 2016). Nesta análise, foi observada a presença de infiltrado inflamatório, o tipo de célula inflamatória predominante em cada fase, deposição de fibrina e tecido conjuntivo, bem como reposição da camada epidérmica.

Este projeto foi aprovado pelo Comitê de Ética sob o $\mathrm{n}^{\circ} \mathrm{PM}$ 09/2017 / CEUA - UNINGÁ. 


\section{Resultados}

Nas análises clínicas, não se observou em nenhum momento conteúdo purulento, e nos três primeiros dias de pós-operatório, as lesões do grupo controle se apresentavam hiperêmicas enquanto no grupo tratado, as membranas tinham aspecto úmido e transparente. No grupo controle, ao quarto dia, foi possível observar início de formação de tecido de granulação, e ao quinto dia formação de crostas. No grupo tratado, a partir do sétimo dia de pós-operatório, as membranas começaram a ressecar e se soltar da ferida em algumas regiões (Figura 3).

No $11^{\circ}$ dia, $18 \%$ dos ratos dos grupos que receberam a membrana removeram os pontos e a membrana de sua ferida. No $14^{\circ}$ dia pós-cirúrgico, as crostas do grupo controle se tornaram mais escuras e teve início a cicatrização nas bordas da ferida em todos os grupos.

Ao $17^{\circ}$ dia, no grupo controle, a pele estava completamente cicatrizada, enquanto no grupo tratado ainda faltava o centro da ferida ser cicatrizado, sendo observada presença de crostas, além de que, nenhum animal possuía a membrana em sua ferida, visto que em todos os casos a membrana ressecou e se soltou (Figura 4).

No momento da eutanásia, em todos os tempos de observação, macroscopicamente, foi possível constatar que as feridas craniais em todas as fases de ambos os grupos apresentaram maior aderência (Figura 5). Na avaliação histológica foi constatada presença de grande infiltrado inflamatório nos períodos iniciais de três e sete dias, no entanto, ao terceiro dia em ambos os grupos foi possível observar dermatite aguda difusa com presença de fibrina e composta predominantemente por neutrófilos, enquanto que em ambos os grupos no período de sete dias foi observada dermatite crônica ativa com áreas hiperêmicas e presença prevalente de neutrófilos, mas também apresentando células mononucleares, além de deposição de tecido conjuntivo no grupo membrana. (Figura 6).

Após 14 dias do procedimento cirúrgico, as feridas de ambos os grupos já apresentavam reposição da camada epidérmica, a qual se encontrava espessada e com resquícios de crosta, além disso, o processo inflamatório já se apresentava mais discreto, mas ainda com presença de células inflamatórias principalmente linfohistiocitárias. Também foi possível observar maior deposição de tecido conjuntivo, principalmente no grupo membrana (Figura 7).

Por fim, decorridos 21 dias de pós-operatório foi verificado que a epiderme já se encontrava cicatrizada tanto no grupo membrana quanto no grupo controle (Figura 7).

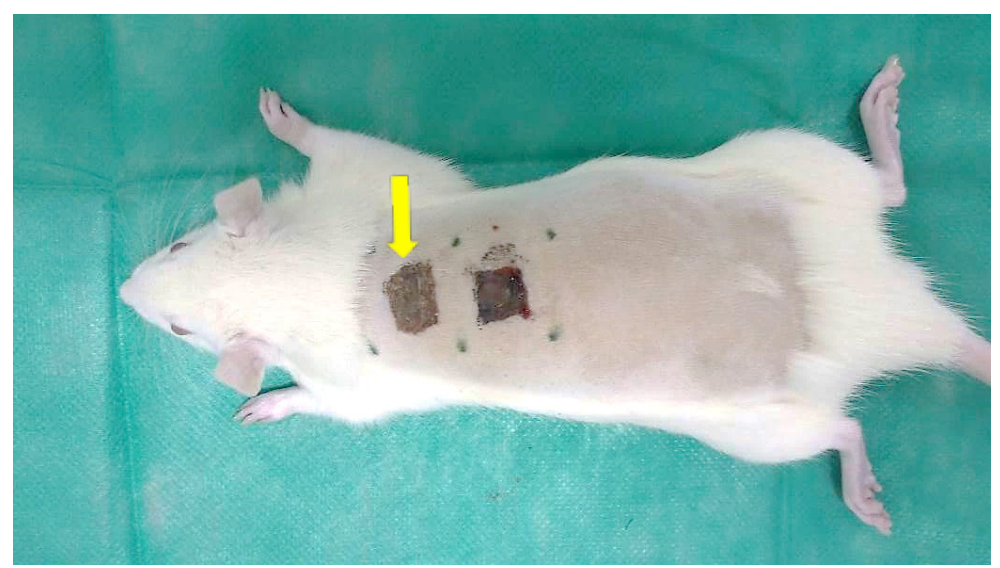

Figura 3: Imagem fotográfica pós-operatória de ratos Wistar. Presença de tecido de granulação e formação de crosta na ferida controle (seta)

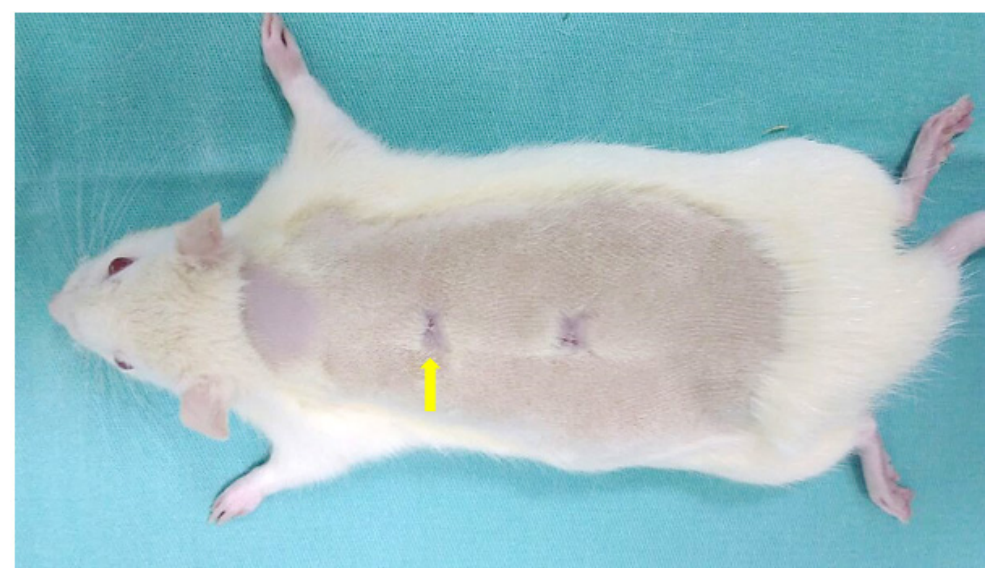

Figura 4: Imagem fotográfica pós-operatória de rato Wistar. Pode-se observar que a ferida cranial que havia recebido a membrana ainda possui crosta no centro (seta), enquanto a ferida controle (caudal) já está cicatrizada. 


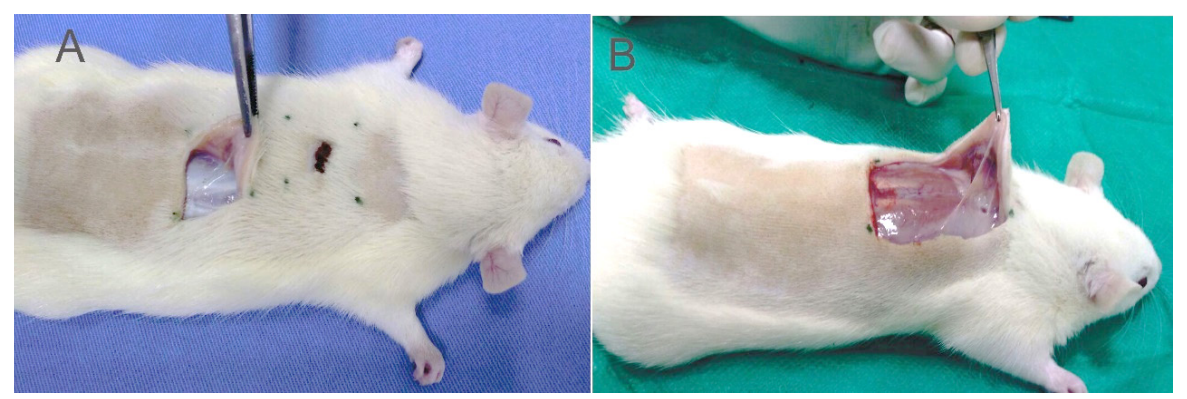

Figura 5: Imagens fotográficas pós-operatórias de ratos Wistar. Nota-se na imagem B maior aderência na ferida cranial do que na ferida caudal em $A$.

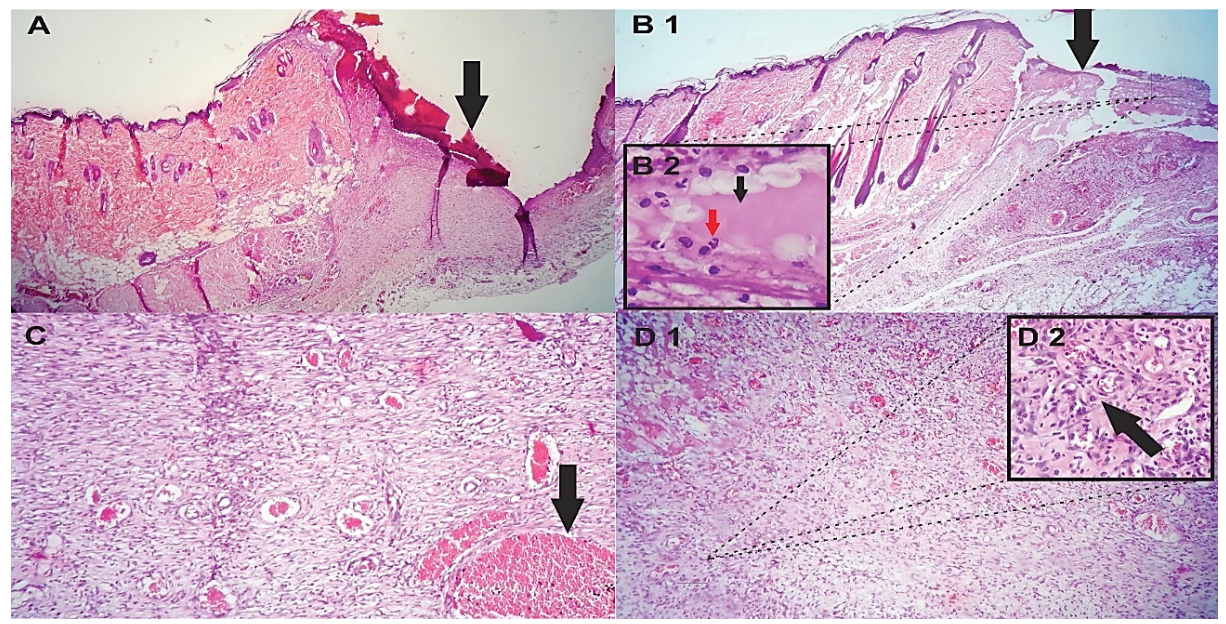

Figura 6: Imagens de microscopia de feridas de ratos Wistar. A) Grupo Controle com 3 dias em aumento de 4x. Observa-se na seta preta, grande área de ulceração com deposição de fibrina B1) Grupo Membrana com 3 dias em aumento e $4 x$, observa-se (seta preta) uma ulceração menor quando comparada ao grupo controle, B2) Aumento de $40 \mathrm{X}$, observa-se presença de infiltrado inflamatório composto por neutrófilos (seta vermelha) e presença de edema seta preta. C) Grupo Controle com 7 dias em aumento de 10x. observa-se hiperemia (seta preta). D) Grupo Membrana com 7 dias em aumento de 10x. nota-se dermatite crônica ativa com presença de neutrófilos e células mononucleares, deposição de tecido conjuntivo (seta preta) e hiperemia.

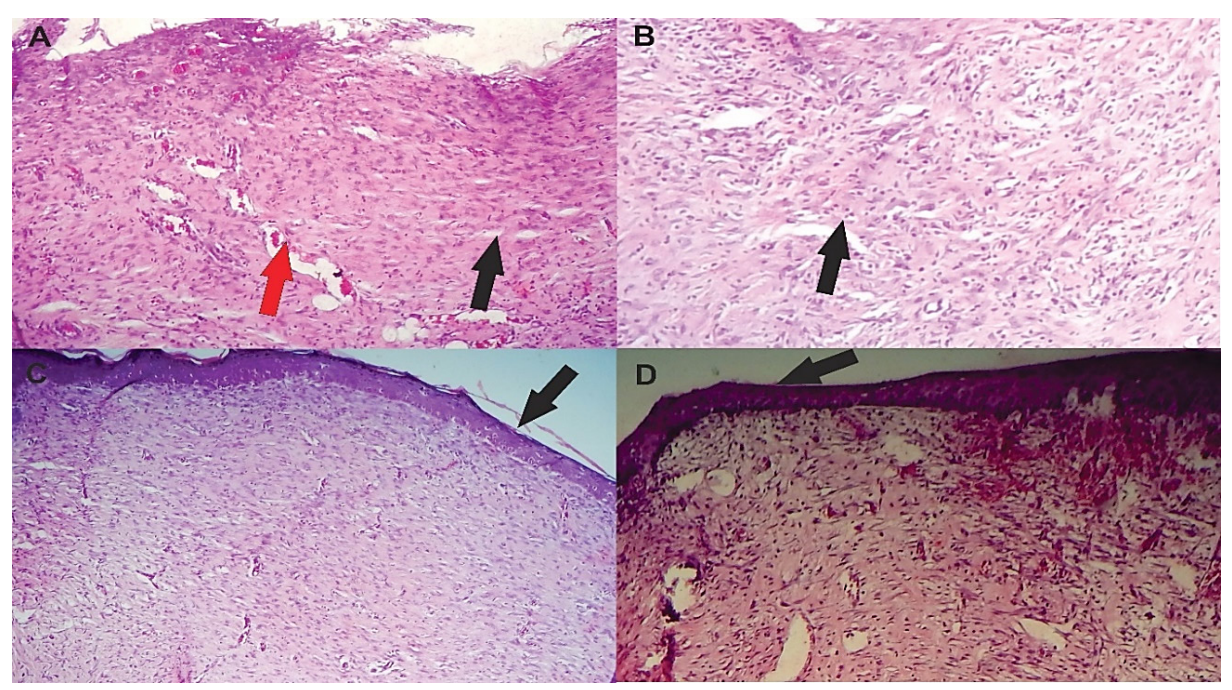

Figura 7: Imagens de microscopia de feridas de ratos Wistar. A) Grupo controle com 14 dias em aumento de 10x observa-se deposição de tecido conjuntivo (seta preta) e hiperemia (seta vermelha). B) Grupo membrana com 14 dias em aumento de 10x. (B) Nota-se maior deposição de tecido conjuntivo no grupo membrana (seta preta). C) Grupo controle com 21 dias em aumento de 10x. D) Grupo Membrana com 21 dias em aumento de 10 x. Observa-se que em ambos os grupos (C e D) com 21 dias a epiderme já se encontrava reposta. 


\section{Discussão}

A túnica vaginal tem apresentado bons resultados como enxerto biológico em diversos procedimentos reconstrutivos (Galera et al., 2000; Vicenti et al., 2002; Foinquinos et al., 2007; Wongsetthachai et al., 2011; Faria et al., 2020). No entanto, de acordo com Chem et al. (1992), Olsson et al. (2008) e Oliveira et al. (2008), os tecidos xenogênicos, ou seja, aqueles obtidos de uma espécie diferente a do receptor, mesmo propiciando arcabouço para a formação do tecido cicatricial, frequentemente levam à expulsão da membrana, o que corrobora o resultado obtido neste trabalho, no qual a membrana orientou o tecido cicatricial, não se aderiu a ferida, e foi expelida em todos os animais.

A glicerina a $98 \%$ vem sendo vastamente utilizada como conservante em experimentos, assim como no presente estudo, demonstrando bons resultados. Dentre suas propriedades, destaca-se a capacidade de desidratação celular, sem alterar a concentração iônica e, consequentemente, a integridade da célula (Pigossi, 1964; Daleck et al., 1988). Dessa forma, atua contra fungos e bactérias gram-positivas e gram-negativas, exceto formas esporuladas (Pigossi, 1967). Tal propriedade, é confirmada nesse experimento, haja vista que não ocorreu nenhum sinal macroscópico que pudesse ser entendido como processo infeccioso.

Durante os três primeiros dias, as lesões do grupo controle se mostravam hiperêmicas, o que é normal devido à vasodilatação provocada pelos mediadores químicos liberados no momento da lesão, que desencadeiam os sinais inflamatórios característicos da fase inicial do processo de cicatrização (Campos et al., 2007). No grupo que recebeu a túnica vaginal, a coloração transparente e úmida da membrana foi semelhante ao resultado apresentado no tratamento de queimaduras cutâneas de coelhos com peritônio bovino (Busnardo et al., 2009) e no tratamento de feridas cutâneas de equinos com membrana amniótica (Oliveira \& Alvarenga, 1998).

A formação de tecido de granulação no grupo controle ao quarto dia de pós-operatório caracteriza a fase proliferativa da cicatrização, onde ocorre neo-angiogênese, fibroplasia e epitelização.

Dos $18 \%$ dos animais que removeram os pontos e a membrana de sua ferida, $66 \%$ apresentavam a ferida na posição cranial, supondo-se que o animal pode ter alcançado a ferida, já que o mesmo não utilizou nenhum tipo de colar protetor (elisabetano) ou curativo sobre a ferida.

A observação de maior aderência à musculatura no momento da eutanásia nas feridas craniais de ambos os grupos, controle e membrana, pode ser justificado pela maior deposição de gordura existente na região craniodorsal comparada à região mais caudal de ratos.

No momento da eutanásia do grupo de 21 dias, verificou-se a presença de crosta no grupo membrana o que também foi observada com peritônio bovino (Busnardo et al., 2009), e com película celulósica (Woul et al., 1998).

Assim como afirmado por outros pesquisadores (Brun et al., 2002; Busnardo et al., 2009), a presença de hemorragia, vasodilatação, e células polimorfonucleares caracteriza a resposta inflamatória inicial. Em seguida, no período de 7 dias foi observada pouca presença de células mononucleares e transição da dermatite aguda para crônica o que indica a passagem da reação inflamatória para o início da fase proliferativa de cicatrização (Campos et al., 2007; Busnardo et al., 2009).

As membranas biológicas atuam como alicerce, fornecendo estrutura para o crescimento de tecido vivo (Falcão et al., 2002), o que corrobora o resultado apresentado pela túnica vaginal, na qual aos 14 dias de pós-operatório pode-se observar uma maior deposição de tecido conjuntivo, que caracteriza a composição básica da evolução processo cicatricial, quando comparado com o grupo controle (Leal et al., 2014).

Embora tais achados indiquem que a túnica vaginal possa vir a se tornar alternativa para o tratamento de feridas traumáticas pela observação de maior deposição de colágeno e tecido conjuntivo, sugerindo assim uma cicatrização mais precoce deste grupo, acreditamos que a maior limitação do uso da túnica se refira a seu tamanho. O tamanho da túnica vaginal está diretamente relacionado ao tamanho do testículo e pode variar por diversos fatores, entre eles o porte e a idade do cão.

\section{Conclusão}

Concluiu-se que a túnica vaginal canina pode ser utilizada como nova alternativa no tratamento de feridas cutâneas, todavia estudos clínicos futuros deverão ser realizados especialmente em feridas contaminadas e infectadas.

\section{Agradecimentos}

Ao Conselho Nacional de Desenvolvimento Científico e Tecnológico (CNPq) e UNINGÁ - Centro Universitário Ingá, sinceros agradecimentos pelo financiamento do estudo em questão.

\section{Referências}

ABASS, B.T. Túnica vaginal bovina: um novo material para hernioplastia umbilical em ovelhas. Jornal Iraquiano de Ciências Veterinárias, v.22, n.2, p.69-76, 2008.

AMARAL, L.G.; REIS, E.C.C.; FERNANDES, N.A.; BORGES, A.P.B.; VALENTE, F.L.; SEPULVEDA, R.V. Membrana de nanofibras de polímeros biodegradáveis na reparo de feridas cutâneas em cães - relato de dois casos. Semina: Ciências Agrárias, Londrina, v. 37, n. 6, p. 4171-4178, nov./dez. 2016.
BORSARI, F.N.; LEAL, L.M.; FREITAS, H.M.G.; SASAHARA, T.H.C.; MACHADO, M.R.F. Aplicação de membrana de látex natural e extrato de pele de rã (Lithobates catesbiana) em feridas cirúrgicas cutâneas de ratos Wistar. Revista Brasileira de Ciência Veterinária, v.21, n.3, p.150-155, julho-setembro, 2014.

BRUN, M.V.; PIPPI, N.L.; DREIMEIER, D.; CONTESINI, E.A.; BECK, C.A.C.; CUNHA, O.; PINTO FILHO, S.T.L.; ROEHSIG, C.; STEDILE, R. Solução hipersaturada de sal como conservante de pericárdio canino utilizado na reparação do músculo reto abdominal de ratos Wistar. Ciência Rural, v.32, n.6, p.1019-1025, 2002. 
BURGOS, F.R.N.F; LIMA, J.L.S.; ALMEIDA, E.L.; SANTOS, L.G.P.; SILVA JUNIOR, V.A. Pinealectomia em ratos Wistar (Rattus norvegicus albinus): descrição de um novo método cirúrgico. Arquivo Brasileiro de Medicina Veterinária e Zootecnia, v.68, n.1, p.119-126, 2016.

BUSNARDO, C.A.; FREITAS, P.M.C.; EURIDES, D.; RONCETII, G.R.; NUNES, L.C.; BELETTI, M.E. Peritônio bovino como curativo em queimaduras cutâneas experimentais em coelhos. Ciência Animal Brasileira, v.10, n.3, p.823-828, 2009.

CAMPOS, A.C.L.; BORGES-BRANCO, A.; GROTH, A.K. Cicatrização de feridas. ABCD Arq Bras Cir Dig, v.20, n.1, p.51-8, 2007

CASTRO, A.U.; ARGÔLO NETO, N.M.; VIANA, J.A. Uso tópico de mel de abelha, oxitetraciclina e hidrocortisona, na reparação de feridas cutâneas, por segunda intenção, em coelhos. Revista Ceres, Universidade Federal de Viçosa, v.56, n.1, p.38-44, 2009

CHEM, W.Y.J.; ROGERS, A.A.; LYDON, M.J. Caracterização das propriedades biológicas do fluido da ferida coletado durante os estágios iniciais da cicatrização. J Clin Investig Dermato, v.99, p.559-564, 1992.

DALECK, C.R.; ALESSI, A.C.; COSTA NETO, J.M.; DALECK, C.M.; PADILHA FILHO, J. Substituição de retalho diafragmático de cão por peritônio bovino preservado em glicerina: um estudo experimental. Ars Veterinária, v.4, n.1, p.53-61, 1988.

FALCÃO, S.C.; LOPES, S.L.; COELHO, A.R.B.; ALMEIDA, E.L. Pele de Rana catesbeiana como curativo biológico oclusivo no tratamento de feridas cutâneas produzidas em cães: alterações macroscópicas e microscópicas decorrentes da interação desses tecidos - estudo preliminar. Acta Cirúrgica Brasileira, v.17, n.3, p.151-159, 2002.

FARIA, B.G.O.; CAIRES, L.P.; URIBE, A.A.; MERCÊS, G.W.M.S.; MURAMOTO, C.; COSTA NETO, J.M. Túnica vaginal autógena para herniorrafia perineal em cães. Arquivo Brasileiro de Medicina Veterinária e Zootecnia, v.72, n.2, p.323-331, 2020.

FERREIRA, L.M.; HOCHMAN, B.; BARBOSA, M.V.J. Modelos experimentais em pesquisa. Acta Cir Bras [série online], v.20 (Supl. 2), p.28-34, 2005. Disponível em URL: http://www.scielo.br/ acb.

FOINQUINOS, R.C.; CALADO, A.A.; JANIO, R.; GRIZ, A.; MACEDO, J.M.; ORTIZ, V. A. Túnica Vaginalis Dorsal Uretroplastia: Experiência Inicial. Int Braz J Urol, v.33, p.523-531, 2007.

GALERA, P.D.; LAUS, J.L.; FERREIRA, A.L. Uso de túnica vaginal autógena fresca na ceratoplastia lamelar experimental em cães (Canis familiaris, Linnaeus 1758). Brazilian Journal of Veterinary Research and Animal Science, v.3, p.475-479, 2000.

JUNQUEIRA, L.C.; CARNEIRO, J. Histologia Básica. Rio de Janeiro: Guanabara Koogan, 2006.

LEAL, L.M.; FERREIRA, A.R.S.; REIS, A.C.G.; MARTINS, L.L.; GARCIA FILHO, S.P.; MACHADO, R.F. O uso de peritônio de paca preservado em solução supersaturada de açúcar a $300 \%$ ou glicerina a $98 \%$ implantados na parede abdominal de ratos. Arquivo Brasileiro de Medicina Veterinária e Zootecnia, v.66, n.5, p.1383-1391, 2014.

LUCIANO, E.; MELLO, M.A.R. Atividade física e metabolismo de proteínas em músculos de ratos diabéticos experimentais. Revista Paulista de Educação Física, São Paulo, Jul-Dez, 1998.

MARQUEZ, J.A.; MORAES, J.R.E.; TEIXEIRA NETO, F.J. Tratamento alternativo de feridas na papila mamária de vacas usando uma membrana biológica (Biofill) *. Braz J Vet Res Anim Sci., v.33, n.2, p.102-106, 1996.
MONTEIRO, V.L.C.; COELHO, M.C.O.C.; CARRAZZONI, P.G.; MOTA, R.A.; MELO, F.A.D.; CARVALHO, E.C.; ANDRADE, L.S.S. Cana-de-açúcar no tratamento de feridas cutâneas por segunda ou terceira intenção. Medicina Veterinária, Recife, v.1, n.1, p.1-8, jan-jun, 2007.

OLIVEIRA, L.L.; BARATA, J.S.; SILVA, A.V.P.; CARVALHO, E.C.Q.; NUNES, L.C.; ABÍLIO, E.J. Avaliação histológica da túnica albugínea bovina como biomaterial conservado em glicerina 98\% e glutaraldeído 0,625\%. Revista Brasileira de Medicina Veterinária, v.37, n.4, p.309-315, 2015.

OLIVEIRA, T.C.; SCAVONE, A.R.F.; MACHADO, M.R.F.; MAZZUCATO, B.C. Cistoplastia experimental em coelhos (Oryctolagus cuniculus) com peritônio bovino preservado em glicerol 98\%. Cienc Rural, v.38, p.2218-2224, 2008.

OLIVEIRA, V.A.; ALVARENGA, J. Membrana amniótica preservada em glicerina no reparo de feridas cutâneas de membros locomotores de equinos. Ciência Rural, v.28, n.4, p.623-628, 1998.

OLSSON, D.; PIPPI, N.;, TOGNOLI, G.K.; RAISER, A.G. Células progenitoras da medula óssea enriquecem o comportamento biológico do arcabouço no reparo ósseo. Cienc Rural, v.38, n.8, p.2403-2412, novembro de 2008.

PIGOSSI, N. Implantação de dura-máter homógena conservada em glicerina - estudo experimental em cães. Tese (Doutorado em Medicina) - Faculdade de Medicina de São Paulo, Universidade de São Paulo, 1964

PIGOSSI, N. A glicerina na conservação de dura-máter - estudo experimental. Tese (Livre docência) - Faculdade de Medicina de São Paulo, Universidade de São Paulo, 1967.

RAHAL, S.; ROCHA, N.S.; BLESSA, E.P.; IWABE, S.; CROCCI, A.J. Pomada orgânica natural ou solução salina isotônica no tratamento de feridas limpas induzidas em ratos. Ciência Rural, v.31, n.6, p.1007-1011, 2001.

RAISER, A.G.; GRAÇA, D.L.; PIPPI, N.L.; ZINN, L.L.; SILVEIRA,D.S.; BORDIN, A.I.; BAIOTTO, G.C.; RIOS, M.V.; SILVEIRA, A.F. Homoimplante ortotópico de tendão calcâneo em cães. Conservação assepsia e implantação. Ciência Rural, v.31, n.1, p.89-94, 2001.

SCHEFFER, J.P.; ATALLAH, F.A.; GOMES, C.; ESTUPAÑAN, O.F.T.; SILVA, S.J.Q.; SILVA, T.I.R.; VALE, D.F.; OLIVEIRA, A.L.A. Cirurgia reconstrutiva no tratamento de feridas traumáticas em pequenos animais. Revista Brasileira de Medicina Veterinária, v.35 (Supl. 1), p.70-78, 2013.

SILVA, L.A.F.; EURIDES, D.; SILVA, M.A.M.; SILVA, O.C.; RABELO, R.E.; PAULO, N.M.; MARTINS, G.H.L.; SOUSA, J.N. Uso de cartilagem auricular homóloga na correção de hérnia umbilical bovina. Brazilian Journal of Veterinary Research and Animal Science, v.41 (Supl I.), p. 289-290, 2004.

VICENTI, F.A.M.; LAUS, J.L.; COSTA NETO, J.M.; TAGLIERI, I. C.; CAMPOS, C.F.; JORGE, A.T.; FERREIRA, A.L.; FANTINATI, A.P. Uso de túnica vaginal alógena conservada em glicerina $98 \%$ para ceratoplastia em cães. Rev Bras Ciênc Vet, v.9, p.182-187, 2002.

WONGSETTHACHAI P.; PRAMATWINAI, C.; BANLUNARA, W.; KALPRAVIDH, M. Urinary bexiga wall substitution using autologous tunica vaginalis in dog mach. Pesquisa em Ciências Veterinárias, v.90, p.156-159, 2011.

WOUK, A.F.; DINIZ, J.M.; CÍRIO, S.M.; SANTOS, H.; BALTAZAR, E.L.; ACCO, A. Membrana biológica (Biofill囚): estudo comparativo com outros agentes promotores da cicatrização da pele em suínos - aspectos clínicos, histopatológicos e morfométricos. Arquivos de Ciências Veterinárias, v.3, n.1, p.31-37, 1998. 